\title{
Assessing Requirements Engineering Processes with the REAIMS Model: Lessons Learned
}

\author{
Marjo Kauppinen and Sari Kujala \\ Helsinki University of Technology \\ Software Business and Engineering Institute \\ P.O. Box 9600 \\ FIN-02015 HUT, Finland \\ marjo.kauppinen@hut.fi, sari.kujala@hut.fi
}

\begin{abstract}
Organizations are becoming increasingly interested in improving their requirements engineering processes. The assessment of the current situation is the first step towards systematic process improvement. The REAIMS model (Sommerville et al. 1997) has been developed to evaluate the status of existing requirements practices. This paper describes an assessment process and two assessment instruments that can help organizations to use the REAIMS model. We evaluated the model, the process and the instruments by performing an assessment in three organizations. The results of the study indicate that the REAIMS model provides useful information for communication, motivation and process improvement planning. REAIMS assessment results are dependent on assessors, and are therefore not reliable for longterm monitoring and benchmarking as such. A systematic assessment process such as the one described in this paper can improve reliability of assessment results.
\end{abstract}

\section{INTRODUCTION}

Many organizations are becoming convinced that systematic requirements definition and management are essential for developing successful systems. Therefore, an increasing number of companies are interested in improving their requirements engineering (RE) processes. In theory, requirements engineering applies proven principles, techniques, languages, and tools to help analysts describe a product's external behavior (Davies et al. 1994). However, in practice organizations often find it difficult to know how to start improving their RE processes.

An important activity in systematic process improvement is to assess the state of current practice (ISO/IEC 15504-1 1998, ISO/IEC 15504-7 1998, Zahran 1998). The assessment provides information on the basis of which organizations can set realistic improvement goals and plan practical improvement actions. The REAIMS (Requirements Engineering Adaptation and IMprovement for Safety and dependability) project has developed a requirements process maturity model (Sommerville et al. 1997). This REAIMS model is unique in focusing specifically on RE assessment. It contains 66 requirements practices covering eight $\mathrm{RE}$ areas (Sawyer et al. 1999a).

An assessment process and assessment instruments help organizations when they analyze their RE practices against the REAIMS model. A documented process supports repeatability of an assessment approach and provides the basis for continuous improvement (ISO/IEC 15504-4 1998). Instruments and tools can provide valuable support when assessment information is collected, recorded, analyzed, and presented (ISO/IEC 15504-4 1998).

This paper describes an assessment process that combines tasks from the ISO/IEC 15504 assessment process (ISO/IEC 15504-3 1998) and from the generic assessment process (Zahran 1998). We also introduce two assessment instruments: a REAIMS questionnaire and a report template.

As far as we know, no empirical studies conducted on the REAIMS model have been published. The goals of this study are to evaluate the usefulness of the REAIMS model and to analyze how the assessment process and instruments help organizations to use the REAIMS model. In order to obtain empirical data, we performed an assessment in three organizations. The main contribution of this paper is the description of lessons learned from these three cases.

The paper is structured as follows. In the next section, the REAIMS model is explained in brief. Then, we introduce the assessment process and instruments. The three assessment cases are presented in the fourth section and the lessons learned from these cases are described in the fifth section. Finally, our conclusions are presented.

\section{OVERVIEW OF THE REAIMS MODEL}

In comparison with the CMM and other software process improvement (SPI) standards, the REAIMS model is unique in focusing specifically on RE processes. In contrast to the CMM, the REAIMS model has only three maturity levels. This is because the current state of the practice makes it doubtful whether any requirements processes exist that could be characterized beyond level 3 (Sawyer et al. 1999a). 
The levels of the REAIMS model are called initial, repeatable and defined (Sommerville et al. 1997, Sawyer et al. 1999b). Initial-level organizations have an ad hoc RE process and requirements problems are common. Repeatable-level organizations have defined standards for requirements documents and the quality of their requirements documents is good. Organizations that are at the defined level have documented RE process models based on good practices and the quality of the requirements documents is constantly high.

The REAIMS model includes eight RE areas and sixty-six RE practices (Sommerville et al. 1997, Sawyer et al. 1997). The RE areas and the number of the RE practices within each area are listed in Table 1. The REAIMS model has been developed for critical systems but most of the RE areas and the RE practices are also generically applicable. Critical systems are systems whose failure can threaten human life or can significantly disrupt the running of an organization (Sommerville et al. 1997). The practices of the model have been abstracted from existing standards, reports of requirements practices, and the experience of practitioners (Sawyer et al. 1999a).

\begin{tabular}{|l|l|}
\hline $\begin{array}{l}\text { RE Area of the REAIMS } \\
\text { model }\end{array}$ & $\begin{array}{l}\text { Number of } \\
\text { RE practices }\end{array}$ \\
\hline \hline Requirements document & 8 \\
\hline Requirements elicitation & 13 \\
\hline Requirements analysis & 8 \\
\hline Requirements representation & 5 \\
\hline Requirements validation & 8 \\
\hline Requirements management & 9 \\
\hline System modeling & 6 \\
\hline RE for critical systems & 9 \\
\hline
\end{tabular}

Table 1: RE areas and number of RE practices within each RE area

The practices of the REAIMS model have been classified into three categories (Sommerville et al. 1997). Basic practices are relatively simple activities concerned with standardization, management, and usability. Intermediate practices are mostly concerned with the introduction of systematic and structured RE methods. Advanced practices are intended to support the continuous improvement of RE processes, and they require specialist expertise. At the moment, the REAIMS model includes 36 basic practices, 21 intermediate practices and 9 advanced practices (Sawyer et al. 1999a).

\section{ASSESSMENT PROCESS AND INSTRUMENTS}

A documented assessment process supports repeatability of an assessment approach and provides the basis for continuous improvement (ISO/IEC 15504-4 1998). According to the REAIMS model, the assessment process includes five phases (Sommerville et al. 1997). In the first phase, practices that are obviously never used are eliminated from the checklists. Then, interviewees are identified. The third phase involves initial scoring, which should be "quick and dirty", and based on checklists. After this "quick and dirty" assessment, uncertainties are resolved (Sawyer et al. 1997). The final maturity level is calculated by summing the numerical scores for each practice (Sawyer et al. 1999a).

The assessment process of the REAIMS model was too informal for our purposes because it offers too little guidance for repeatable and reliable assessment. To guide our formal assessment in three organizations, we defined a process presented in Table 2. This process combines tasks from the generic assessment process (Zahran 1998) and the ISO/IEC 15504 process (ISO/IEC 15504-3 1998).

\begin{tabular}{|c|c|}
\hline Phase & Tasks \\
\hline Planning & 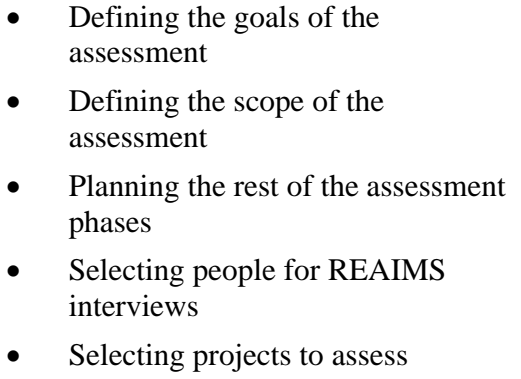 \\
\hline $\begin{array}{l}\text { Data } \\
\text { collection }\end{array}$ & 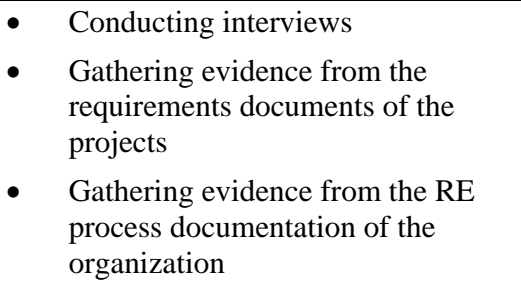 \\
\hline $\begin{array}{l}\text { Data } \\
\text { analysis }\end{array}$ & $\begin{array}{l}\text { - } \begin{array}{l}\text { Recording and analyzing interview } \\
\text { data }\end{array} \\
\text { - } \\
\text { Recording and analyzing the } \\
\text { evidence gathered from the RE } \\
\text { documentation }\end{array}$ \\
\hline Reporting & $\begin{array}{l}\text { - } \begin{array}{l}\text { Documenting the assessment } \\
\text { results }\end{array} \\
\text { - } \quad \text { Presenting the assessment results in } \\
\text { a workshop }\end{array}$ \\
\hline
\end{tabular}

Table 2: Assessment process of the study

The purpose of the planning phase is to define why the assessment will be performed and how extensive it will be. In the data collection phase, people are interviewed and information is also obtained from the requirements documentation. After the data has been collected, it must be analyzed as objectively as possible. Based on the analyzed information, an assessment report is written and the assessment results are also presented in a workshop.

Assessment instruments and tools can provide valuable support when assessment information is collected, recorded, analyzed and presented (ISO/IEC 15504-4 1998). We developed the REAIMS questionnaire, which can be used to support the data collection phase (Figure 1). We also defined the 
report template, which can help assessors to document assessment results (Figure 1). The developers of the REAIMS model have written the Requirements Engineering Good Practice Guide, also known as the REGPG (Sommerville et al. 1997). The REGPG describes all sixty-six RE practices and its main purpose is to provide guidance for RE process improvement. The REGPG can also be used in the data analysis phase (Figure 1). It helps assessors to interpret whether a certain practice is used or not within an organization.

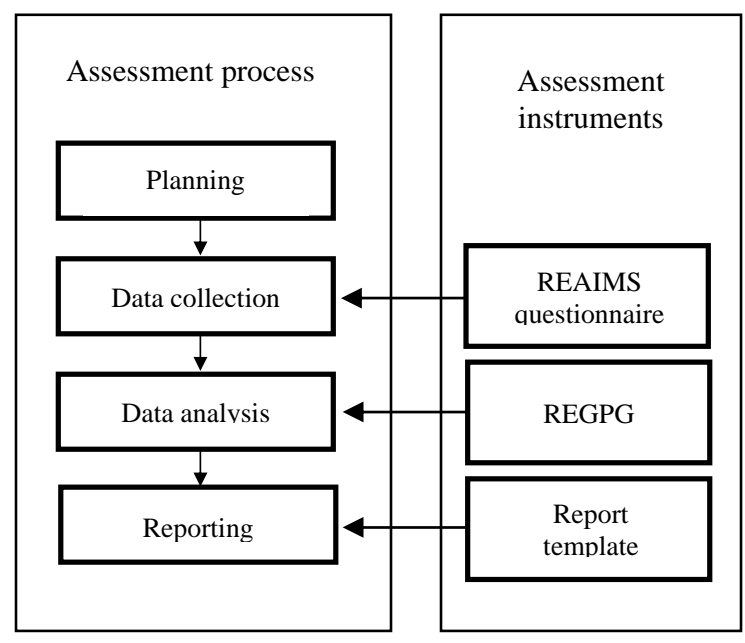

Figure 1. Assessment instruments of the study

The developers of the REAIMS model have defined three checklists to help organizations in the assessment activity (Sommerville et al. 1997). After testing the checklists, we designed a questionnaire based on them. The purpose of the questionnaire is to make data collection faster and more reliable. The practices are described in brief in the checklists (see examples in Table 3). During testing, we had to read the longer descriptions of the practices several times in order to be able to judge if practices are used. For the questionnaire, we formulated the questions more precisely (see examples in Table 3). We also added footnotes to explain terms used in the questionnaire.

\begin{tabular}{|l|l|}
\hline $\begin{array}{c}\text { Question of the REAIMS } \\
\text { questionnaire }\end{array}$ & \multicolumn{1}{c|}{$\begin{array}{c}\text { Practice of the } \\
\text { checklists }\end{array}$} \\
\hline \hline $\begin{array}{l}\text { Is a standard structure used in } \\
\text { requirements documents? }\end{array}$ & $\begin{array}{l}\text { Define a standard } \\
\text { document structure }\end{array}$ \\
\hline $\begin{array}{l}\text { Do requirements documents } \\
\text { include a section that explains } \\
\text { how the document should be } \\
\text { used? }\end{array}$ & $\begin{array}{l}\text { Explain how to use the } \\
\text { document }\end{array}$ \\
\hline $\begin{array}{l}\text { Do requirements documents } \\
\text { include a business case, i.e. a } \\
\text { section explaining why the } \\
\text { system is required and what the } \\
\text { business objectives of the } \\
\text { system are? }\end{array}$ & $\begin{array}{l}\text { Make a business case } \\
\text { for the system }\end{array}$ \\
\hline
\end{tabular}

Table 3: Example questions of the REAIMS questionnaire related to the practices of the original checklists
We defined a template for reporting assessment results. The report template consists of three parts: 1 ) the introduction, 2) the REAIMS model, and 3) the assessment results. The introduction part defines the goals, the scope, and the period of the assessment. The REAIMS model is introduced briefly in the second section of the report. This helps readers to understand the assessment results.

In the report template, assessment results are divided into three categories: 1) RE maturity rating, 2) RE process profile, and 3) state of RE practices. The RE maturity rating (see the example in Table 4) provides overall information on the current state of the practice. The RE process profile (see the example in Figure 2) permits practitioners to examine and compare all eight requirements engineering areas. The state profiles of RE practices (see the example in Figure 3) show which requirements practices are in use and to what extent.

\section{THE CASES}

The goals of this study were to evaluate the usefulness of the REAIMS model and to analyze how the assessment process and instruments help organizations to use the REAIMS model. We evaluated the model, the process and the instruments by performing an assessment in three Finnish organizations. All the organizations were product development units of medium-size or large companies and the number of employees of these units varied from 110 to 160 . Two of the organizations develop interactive systems and one of them real-time embedded systems. Here, we report our experience of deploying the REAIMS model, the assessment process and instruments in the three organizations.

Planning phase. In the start-up meeting, each organization defined the assessment goals and decided to conduct a formal assessment using the REAIMS model and the four-phase assessment process. Because the organizations wanted to measure the progress of the coming improvement actions, their main assessment objective was to set a baseline for long-term monitoring. All the organizations also wanted to use the assessment results for benchmarking their RE process.

In the second meeting, each organization decided that the scope of the assessment should be the whole product development organization. They selected one experienced person from each department to participate in the REAIMS interviews.

Each organization also decided that the RE practices of three on-going projects would be analyzed. The analysis was performed by interviewing the persons who had been responsible for defining the requirements and by assessing the requirements documents of the projects.

Data collection phase: The first step of the data collection phase was to interview the department representatives using the REAIMS questionnaire. The 
purpose of the REAIMS interviews was to define quickly the current state of the RE process and discover whether practitioners found the sixty-six RE practices of the REAIMS model suitable for their organization.

After the REAIMS interviews, we analyzed the $\mathrm{RE}$ practices of the three projects in each organization. We interviewed at least on person from each project. Because our purpose was to find out how requirements are defined and managed in practice, we interviewed the persons who had been responsible for writing the requirements documents. In addition, we evaluated the requirements documents of the projects and analyzed the RE process documentation of each organization. The purpose of the in-depth interviews and document analysis was to understand fully the current state of the existing RE processes and find evidence of the RE practices used in the organization.

Data analysis phase: After the interviews and the document studies, the questionnaire responses and the evidence of the existing $\mathrm{RE}$ practices were documented. Based on the collected information, we analyzed the state of the sixty-six RE practices using the REGPG. We read each practice description of the REGPG thoroughly and judged whether a certain practice was used or not in the organization. Finally, the RE maturity rating was calculated.

Reporting phase: The assessment results were reported at three levels: 1) RE process maturity rating, 2) RE process profile, and 3) state of RE practices. Table 4 shows an example of how the highlevel results were presented. The RE process maturity rating was calculated by summing the numerical scores for each RE practice. The number of the basic $\mathrm{RE}$ practices is thirty-six and the highest score for a $\mathrm{RE}$ practice is three. Thus, the maximum score of the basic RE practices is 108 points. The requirements engineering processes of an organization are at the initial level if the assessment score of the basic RE practices is less than 55 points (Sommerville et al. 1997).

\begin{tabular}{|l|c|}
\hline & Organization A \\
\hline \hline RE process maturity rating & Initial \\
\hline Score of basic RE practices & $\begin{array}{c}19 \text { points / } \\
108 \text { points (maximum) }\end{array}$ \\
\hline $\begin{array}{l}\text { Score of intermediate and } \\
\text { advanced RE practices }\end{array}$ & $\begin{array}{c}10 \text { points / } \\
90 \text { points (maximum) }\end{array}$ \\
\hline
\end{tabular}

\section{Table 4: Example of the RE process} maturity rating

Figure 2 shows how the RE process profile was presented in the assessment report. The RE area codes used in Figure 2 are as follows:

1) requirements document

2) requirements elicitation

3) requirements analysis

4) requirements representation
5) requirements validation

6) requirements management

7) system modeling

8) RE for critical systems.

First, we calculated the actual points for a RE area by summing the numerical scores of its RE practices and dividing the actual score of the area by its maximum points. Each RE practice can give a maximum of three points. For example, as the requirements representation area includes five practices, its maximum score is fifteen. Because each RE area includes various numbers of RE practices, the proportional scores were used. In Figure 2, the RE areas are comparable to each other and we can see that system modeling is the strongest area and requirements analysis is the weakest.

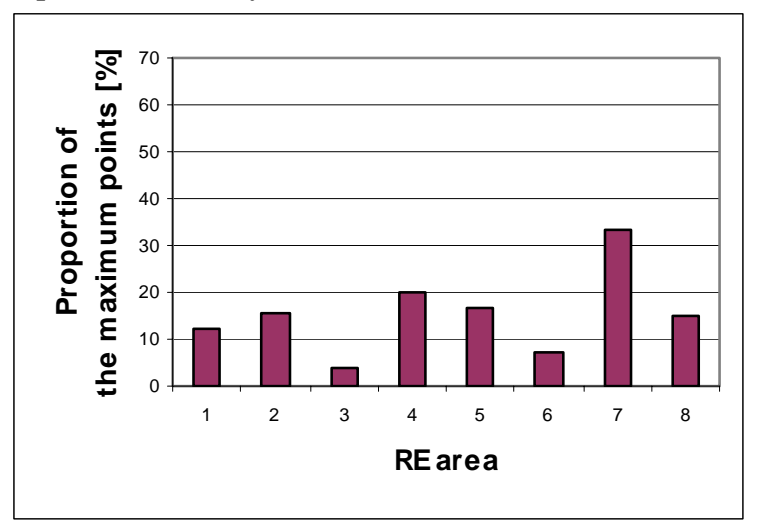

\section{Figure 2. Example of the RE process profile}

Figure 3 shows an example of how the assessment results of the sixty-six practices were presented in the report. The report includes eight state profiles, one for each RE area. Figure 3 presents the state profile of the requirements representation practices. The RE practice codes are as follows:

1) Are standard templates used for representing individual requirements?

2) Are requirements written using simple, consistent, and concise language?

3) Are diagrams used appropriately?

4) Is natural language supplemented with other descriptions of requirements?

5) Are requirements specified quantitatively?

The usage scope codes of Figure 3 mean the following:

0) Never: The practice is never or very rarely applied.

1) Sometimes: Some project managers may have introduced the practice but it is not widely used.

2) Normally: The practice is widely used but it is not mandatory.

3) Systematically: The practice has a documented standard in the organization and it is checked as part of the quality management process.

The assessment results were presented in a workshop. The purpose of the workshops was to analyze the assessment results, set goals for RE 
process improvement, and select improvement areas. One of the organizations had a half-day session and two of them a whole day session. In Organization A, the manager of the improvement project invited the persons willing to be members of the RE process improvement project to the workshop. In Organization B, the department and project managers participated in the workshop. In Organization $C$, the participants in the assessment and the owners of the $\mathrm{RE}$ processes were invited to analyze the assessment results and to plan improvement actions.

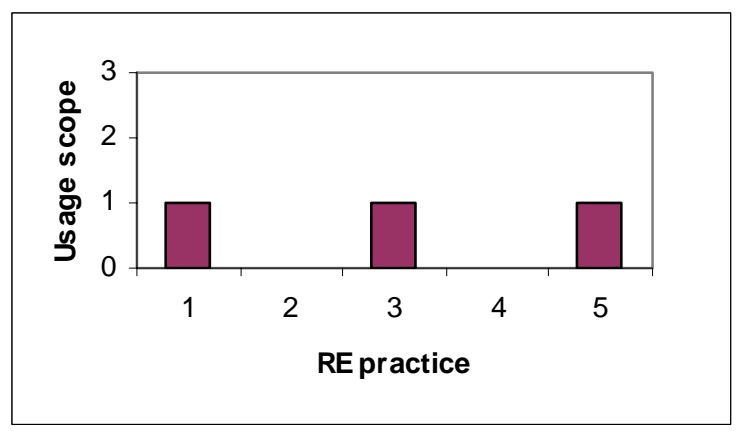

Figure 3. Example of the state of the RE practices

\section{LESSONS LEARNED}

The authors participated actively in the assessments. In addition to involvement in the assessments, observations, informal conversations, formal interviews, official meetings and document studies were used as methods for collecting the data, on which the lessons learned are based.

REAIMS model: The lessons we learned from using the REAIMS model:

- The RE maturity level raises personnel awareness of the quality of the existing $\mathrm{RE}$ practices. It also motivates practitioners for $\mathrm{RE}$ process improvement.

- The scores of the basic, intermediate and advanced RE practices (Table 4) provide a more effective basis for tracking improvements and making progress visible than the overall maturity level.

- The RE process profile (Figure 2) permits practitioners to examine the eight requirements engineering areas and see how they compare. Based on the RE process profile, organizations can identify their strengths and weaknesses.

- $\quad$ The state profiles of the RE practices (Figure 3) help practitioners to judge which requirements practices are in use and to what extent, and to identify the most critical improvement actions.

- The results of REAIMS assessments are subjective and dependent on how assessors interpret the practice descriptions of the REGPG. To improve the reliability of the REAIMS assessments, the model needs to be equipped with a set of indicators that define the kind of evidence from each RE practice that assessors must search for. The indicators would help assessors to interpret the RE practice descriptions more unambiguously. Reliability is particularly important when organizations want to use assessment results for long-term monitoring and benchmarking.

- The REAIMS model seems to be suitable for both interactive and embedded systems. There were only four RE practices that more than one out of the nineteen interviewees found irrelevant for their organization. We also asked the participants of the REAIMS interviews how well the entire set of the RE practices of the REAIMS model suits their organizations. The results are in Table 5. The values of the table represent the number of persons, the total number of respondents being 19 .

\begin{tabular}{|l|c|c|c|}
\hline How well do the REAIMS & \multicolumn{3}{|c|}{ Organization } \\
practices suit the organization? & A & B & C \\
\hline \hline Very well & 1 & 1 & 0 \\
\hline Well & 1 & 3 & 3 \\
\hline Reasonably & 2 & 6 & 1 \\
\hline Poorly & 0 & 0 & 0 \\
\hline Very poorly & 0 & 0 & 0 \\
\hline I cannot say at the moment & 1 & 0 & 0 \\
\hline
\end{tabular}

Table 5: Suitability of the REAIMS practices. The values of the table represent the number of the respondents.

Conducting an assessment with the REAIMS model can be particularly useful for organizations that are just starting improvement of their RE processes. The REAIMS model introduces the eight $\mathrm{RE}$ areas and the sixty-six good RE practices. This kind of information helps organizations that do not know where to start improving their RE processes. REAIMS assessments also improve communication within organizations because they propagate information about successful RE practices across departments and projects.

Assessment process: The lessons we learned about how the assessment process influenced the assessment results are as follows:

- The more reliable assessment results need to be, the more systematic must be the assessment process. In particular, evidence gathering, analysis and recording improve the reliability and repeatability of assessment results.

- A thorough REAIMS assessment requires at least one man-week's effort. The data collection and the data analysis phases are time-consuming. Gathering and analyzing the data would be faster if the REAIMS model included a set of indicators that helped assessors to interpret the RE practice descriptions of the REGPG.

- To convert the assessment findings into recommendations and further into improvement actions is difficult and requires time, effort, and 
expertise of requirements engineering. Organizations need guidelines on how to plan the improvement actions based on assessment results.

We do not recommend organizations to use REAIMS assessment results for long-term monitoring and benchmarking as such because results are dependent on assessors. Evidence recording improves the reliability and repeatability of assessment results. Assessors need to document the data on which they base the score given for each of the sixty-six RE practices. Objective evidence supports the assessors' judgements and provides the basis for verification of assessment results.

Assessment instruments: Our experience in using the REAIMS questionnaire and the report template can be summarized as follows:

- The organizations found that answering the REAIMS questionnaire was a good way to raise personnel awareness of requirements engineering and to motivate them for RE process improvement. For example, the project manager of Organization $B$ decided to increase the number of interviewees from four to eleven after he had answered the REAIMS questionnaire himself.

- The REAIMS questionnaire can be completed quickly. The answering time of the questionnaire varied from 22 minutes to 126 minutes; the average was 46 minutes. This partly explains why the interviewees found answering the REAIMS questionnaire a good way to get to know what the good RE practices are.

- In all three organizations, the quick assessment based on only the REAIMS questionnaire gave clearly higher scores than the detailed assessment (Table 6). We assume that there are three main reasons for the difference. Firstly, the questions based on the REAIMS practices are not unambiguous enough and respondents must interpret the questions. Secondly, even experienced practitioners of medium-sized organizations have difficulties knowing how widely a certain RE practice is used. The third reason for the difference seems to be that practitioners lack information about how to apply a certain RE practice correctly.

- The report template must include a section for improvement recommendations. This kind of information supports the planning of improvement actions.

If an organization is only interested in raising personnel awareness of the good RE practices, it can conduct a lightweight assessment using the REAIMS questionnaire. If an organization wants to invest in requirements engineering and monitor the impact of the improvement efforts, we recommend that it conducts a REAIMS assessment using a systematic assessment process.

\begin{tabular}{|c|c|c|c|c|c|c|}
\hline & \multicolumn{6}{|c|}{ Organization } \\
\hline & \multicolumn{2}{|c|}{ A } & \multicolumn{2}{|c|}{$B$} & \multicolumn{2}{|c|}{ C } \\
\hline & Quick & Detailed & Quick & Detailed & Quick & Detailed \\
\hline $\begin{array}{l}\text { Basic } \\
\text { practices }\end{array}$ & 31 & 19 & 46 & 16 & 32 & 14 \\
\hline $\begin{array}{l}\text { Intermediate } \\
\text { \& advanced } \\
\text { practices }\end{array}$ & 24 & 10 & 26 & 8 & 14 & 6 \\
\hline $\begin{array}{l}\text { RE maturity } \\
\text { level }\end{array}$ & 1 & 1 & 1 & 1 & 1 & 1 \\
\hline
\end{tabular}

Table 6: Scores of the quick and the detailed assessments

\section{CONCLUSIONS}

This paper has described an actual experience of RE process improvement in three organizations. One of our main conclusions is that the REAIMS model provides useful information for communication, motivation and process improvement planning. The model introduces the RE areas, and practitioners can gain an overall view of requirements engineering using it. The model also describes a set of good RE practices based on which organizations can select improvement actions.

Organizations are also interested in using the REAIMS model for long-term monitoring and benchmarking. We do not recommend practitioners to use the model for these purposes as such. To ensure the reliability and repeatability of assessment results, the REAIMS model needs to be developed further by equipping it with a set of indicators that help assessors to judge the state of the RE practices objectively. A systematic assessment process such as the one described in this paper also improves the reliability of assessment results.

The results of this study indicate directions for further investigation. One important challenge in the long term is to evaluate how the different RE practices of the REAIMS model influence the quality of products and the quality of product development projects. We are extending our research into two directions. Firstly, we are observing and analyzing how the organizations that participated in this study are improving their RE processes and how the selected improvement actions will influence the quality of requirements documents. Secondly, we are working on analyzing and modeling critical success factors for incremental RE process improvement.

\section{ACKNOWLEDGEMENT}

The authors would like to thank the participating organizations for their cooperation and willingness to share their experiences and data. We also thank Jyrki Kontio and Casper Lassenius at Helsinki University of Technology and Pete Sawyer at Lancaster University for their valuable comments. This work is mainly funded by Technology Development Center Finland (TEKES). 


\section{REFERENCES}

Davies, A. M. and Hsia, P., "Giving Voice To Requirements Engineering." IEEE Software, March, 1994, pp 12-15.

ISO/IEC TR 15504-1: Information technology Software process assessment - Part 1: Concepts and introductory guide, Technical report, Reference number ISO/IEC TR 155041:1998(E), 1998.

ISO/IEC TR 15504-3: Information technology Software process assessment - Part 3: Performing an assessment, Technical report, Reference number ISO/IEC TR 155043:1998(E), 1998.

ISO/IEC TR 15504-4: Information technology Software process assessment - Part 4: Guide to performing assessments, Technical report, Reference number ISO/IEC TR 155044:1998(E), 1998.

ISO/IEC TR 15504-7: Information technology Software process assessment - Part 7: Guide for use in process improvement, Technical report, Reference number ISO/IEC TR 155047:1998(E), 1998.

Sawyer, P., Sommerville, I. and Viller, S., "Requirements Process Improvement Through the Phased Introduction of Good Practice." Software Process - Improvement and Practice, Vol. 3, (1) 1997, pp 19-34.

Sawyer, P., Sommerville, I. and Viller, S., "Capturing the Benefits of Requirements Engineering." IEEE Software, March/April, 1999, pp 78-85.

Sawyer, P., Sommerville, I. and Kotonya, G., "Improving Market-Driven RE Processes." Proceedings of International on Product-Focused Software Process Improvement (Profes'99), Oulu, Finland, June, 1999, pp 222 - 236.

Sommerville, I. and Sawyer, P., Requirements Engineering - A Good Practice Guide, John Wiley \& Sons, New York, 1997.

Zahran, S., Software Process Improvement: Practical Guidelines for Business Success, Addison Wesley, 1998.

\section{BIOGRAPHY}

Marjo Kauppinen has fourteen years' experience in software and systems engineering. She is currently a researcher in the "Quality through Requirements" (Qure) project at the Helsinki University of Technology, Finland. Before joining the Helsinki University of Technology, Marjo Kauppinen spent 12 years working in industry as a software engineer, systems analyst, and software process developer. She received her $\mathrm{MSc}$ in computer science from the University of Oulu Finland in 1988.

Sari Kujala is a researcher at the Department of Computer Science and Engineering, the Helsinki University of Technology, Finland. She is currently working on the "Quality through Requirements" research project. Sari Kujala has worked with companies and developed rapid and user centered requirements elicitation methods. She received her
MA in Psychology in 1992 and Licentiate of Philosophy in Cognitive Science in 1998 from the University of Helsinki. 